\title{
SISTEM PAKAR DIAGNOSA KERUSAKAN SEPEDA MOTOR YAMAHA MATIC MENGGUNAKAN METODE FORWARD CHAINING
}

\author{
Asep Syaputra ${ }^{1}$, Dedi Setiadi ${ }^{2}$ \\ 1,2Program Studi Teknik Informatika, Sekolah Tinggi Teknologi Pagar Alam, Pagar Alam \\ e-mail:*1asepsyaputra68@sttpagaralam.ac.id, 2dedisetiadi@sttpagaralam.ac.id
}

\begin{abstract}
Abstrak
Sistem pakar adalah sistem berbasis komputer yang memanfaatkan pengetahuan, fakta, dan teknik penalaran untuk mengetahui inti dari masalah yang biasanya hanya dapat diselesaikan oleh pakar pada bidangnya. Pembangunan sistem pakar bertujuan membantu pemakai sepeda motor yamaha matic (user) untuk mengatasi masalah kerusakan pada sepeda motor yamaha matic. Kerusakan sepeda motor Yamaha matic merupakan masalah yang membutuhkan tenaga ahli (teknisi) untuk mengandalkan ilmunya dalam menyelesaikan masalah kerusakan tersebut. Sistem dibangun dengan menggunakan metode forward chaining yang digunakan untuk menguji faktor-faktor masukan dengan menggunakan aturan-aturan yang tersimpan di dalam sistem hingga diperoleh suatu kesimpulan yang diharapkan dengan metode forward chaining ini dapat membantu sistem dalam melakukan diagnosa mesin sepeda motor matic yamaha. Oleh karena itu, dengan menerapkan sistem pakar kerusakan mesin sepeda motor permasalahan kerusakan mesin sepeda motor Yamaha matic dapat diatasi.
\end{abstract}

Kata kunci : Sistem Pakar; Kerusakan Sepeda motor Yamaha; Forward chaining

\begin{abstract}
The expert system is a computer-based system that uses knowledge, facts, and reasoning techniques to solve problems that usually only experts in their field can solve. The development of an expert system is aimed to help Yamaha motorbike users to solve damage problems to a Yamaha Automatic motorcycle. Damage to a Yamaha Automatic motorcycle is a problem that requires experts (technicians) to rely on their knowledge to solve the problem. This system is built using the forward chaining method which is used to test the factors that have been entered by using the rules stored in the system until a conclusion is obtained. By using the forward chaining method, it is hoped that it can help the system in diagnosing the damage to the Yamaha Automatic motorcycle engine. Therefore, by applying an expert system for motorcycle engine damage, the problem of Yamaha Automatic motorcycle engine damage can be resolved.
\end{abstract}

Keywords : Expert System; Yamaha Motorcycle Damage; Forward Chaining 


\section{PENDAHULUAN}

Saat ini, transportasi sudah menjadi syarat yang dibutuhkan masyarakat dalam menjalankan aktivitas sehari-hari. Sebagian besar masyarakat telah menggunakan sepeda motor sebagai angkutan umum, terutama bagi masyarakat di kota-kota besar. Alasan orang menggunakan motor matik sangat menghemat waktu dan biaya dalam pergi ke tempat beraktifitas. Dalam segala aktivitas, terutama di kota besar, masyarakat menuntut untuk melakukan berbagai hal dengan cepat dan tepat. Waktu telah menjadi aset utama yang sangat berharga. Perawatan sepeda motor sebaiknya dilakukan sendiri daripada membawa ke bengkel karna akan memakan banyak waktu. Hal ini sangat membantu, terutama bagi masyarakat yang belum familiar dengan sepeda motor dan tidak sempat menunggu di bengkel hingga motor diperbaiki.

Salah satu jenis motor yang sering mengalami kerusakan adalah motor matic, motor matic akan menunjukkan beberapa tanda sebelum mengalami kerusakan. Jika gejala ini muncul, tindakan korektif akan diambil. Jangan menunggu kerusakan semakin parah, karena dapat memburuk dalam situasi lain. Jika kerusakan menyebar ke komponen lain maka biaya perbaikan akan lebih tinggi. Jika kita terlatih akan mudah mengenali tanda-tanda kerusakan, karena secara umum gejala-gejala tersebut dapat dilihat melalui panca indera[1].

Apabila jenis kerusakan tidak segera ditangani maka akan menjadi masalah yang fatal bagi pengemudi yang tidak mengetahui jenis kerusakan tersebut. Biasanya sebagian pengendara sepeda motor kurang paham akan gangguan atau kerusakan sepeda motor tersebut, terutama kerusakan mesinnya. Belum ada aplikasi sistem pakar untuk mendiagnosis kerusakan mesin sepeda motor. Dewasa ini dengan berkembangnya teknologi informasi maka berbagai bidang perlu diatasi termasuk permasalahan tersebut di atas, yaitu suatu sistem yang dapat digunakan untuk mendiagnosis kerusakan mesin sepeda motor. [2].

Menurut Sisvanto, sistem pakar merupakan program AI (artificial intelligence) yang memiliki basis pengetahuan yang diperoleh dari pakar digital atau expert knowledge, yang dapat memecahkan masalah di bidang tertentu, dan diperoleh kesimpulan. Atau dukungan mesin inferensi terlacak (Mesin Inferensi). Kemudian setelah dilakukan pencarian, berdasarkan pengetahuan, Fakta yang diberikan oleh pengguna sesuai dengan fakta, aturan atau keyakinan yang ada untuk menarik kesimpulan [3]. Sistem pakar dapat memeberikan jawaban dari sebuah permasalahan pada waktu yang konsisten, bahkan dalam beberapa kasus, dapat menarik kesimpulan lebih cepat daripada pakar[4]. Sistem pakar meliputi dua bagian utama, yaitu lingkungan pengembangan dan lingkungan konsultasi. Lingkungan pengembangan digunakan untuk menggabungkan pengembangan pakar ke dalam lingkungan sistem pakar. Non-ahli menggunakan lingkungan konsultasi untuk mendapatkan pengetahuan dan nasihat ahli. Saat ini, kebanyakan sistem pakar tidak menyertakan bagian pengetahuan yang ditingkatkan[5]. Sistem pakar adalah sistem yang berupaya memasukkan pengetahuan manusia ke dalam komputer agar komputer dapat menyelesaikan masalah yang biasanya diselesaikan oleh pakar. Tujuan pengembangan sistem pakar sebenarnya bukan untuk menggantikan peran manusia, tetapi untuk mentransfer ilmu manusia ke sistem agar dapat digunakan oleh banyak orang dan tidak dibatasi oleh waktu[6].

Dengan dibuatkannya penelitian ini diharapkan akan membantu dan mempermudah para pengguna sepeda motor untuk mengetahui apa yang harus diganti dan diperbaiki dari motor tersebut. Dalam pengumpulan informasi tentunya penulis 
merujuk kepada para ahli dibidangnya, sehingga masalah yang dialami oleh para pengguna motor perihal kerusakan pada motor dapat diketahui dan terselesaikan secara baik dan benar.

\section{TINJAUAN PUSTAKA}

\subsection{Sistem Pakar}

Teknologi kecerdasan buatan yang meniru proses penalaran manusia adalah sistem pakar. Biasanya hanya ahli yang bisa memecahkan masalah kompleks. Sistem pakar mencoba menemukan solusi yang memuaskan, meskipun itu bukan solusi terbaik, solusi tersebut cukup untuk melanjutkan pekerjaan[7]. Sistem pakar bertujuan untuk menyelesaikan masalah tertentu dengan meniru keputusan pakar[8]. Sistem pakar pertama kali dikembangkan pada tahun 1970-an, sistem pakar berisi pengetahuan eksklusif. Namun sekarang, istilah "sistem pakar" telah digunakan untuk berbagai sistem yang menggunakan teknologi AI (Artificial Intelegent). Teknologi sistem pakar mencakup bahasa, program, dan perangkat keras sistem pakar, yang dirancang untuk membantu mengembangkan dan membuat sistem pakar[9]. Seorang pakar adalah orang yang memiliki keahlian pada bidang tertentu, yaitu orang yang memiliki pengetahuan atau kemampuan khusus yang tidak diketahui atau tidak dimiliki orang lain di bidangnya masing-masing [10].

Ada 4 macam tipe sistem pakar[11], yaitu:

a. Independen. Jenis sistem pakar ini adalah perangkat lunak independen yang tidak digunakan bersama dengan perangkat lunak lain.

b. Bergabung. Sistem pakar ini adalah bagian dari program yang terdapat dalam algoritma, atau bagian dari program dimana sering disebut dengan algoritma subrutin.

c. Hubungkan ke perangkat lunak lain. Jenis ini biasanya merupakan sistem pakar, seperti $D B M S$ yang terhubung ke paket program tertentu.

d. Sistem pelayanan. Sistem pakar adalah bagian dari komputer khusus yang berkaitan dengan fungsi tertentu. Misalnya: sistem pakar untuk membantu menganalisis data radar.

Karakteristik Sistem Pakar yang baik harus memenuhi karakteristik sebagai berikut:

a. Fasilitas informasi yang handal.

b. Fleksibel untuk dimodifikasi.

c. Bisa digunakan disemua jenis perangkat komputer

\subsection{Motor Matic}

Injeksi adalah metode untuk pencampuran bahan bakar dengan udara Menghasilkan pembakaran yang sempurna pada sepeda motor. Injeksi membutuhkan alat yang disebut injektor, yang memberikan udara ke campuran bahan bakar. Sistem injeksi merupakan salah satu teknologi yang sangat erat kaitannya dengan sistem karburator pada kendaraan yang bergerak. Cara kerja mesin motor matic injeksi adalah pada sistem karburator, kendaraan perlu diatur dengan baik untuk mendapatkan campuran bahan bakar dan udara terbaik atau AFR (air-fuel ratio) dan sistem injeksi diprogram oleh komputer untuk mendapatkan rasio $A F R$ terbaik. Untuk mendapatkan $A F R$ terbaik, injektor memanfaatkan sistem komputer dalam mengontrol AFR. Peralatan elektronik yang digunakan untuk mengontrol pengoperasian injektor disebut ECM atau modul kontrol elektronik[12].

\subsection{Metode Forward Chaining}

Saat menggunakan mesin inferensi, algoritma Forward-chaining adalah salah satu dari dua metode inferensi utama. Algoritma ini dapat secara logis digambarkan sebagai aplikasi siklik dengan cara idiomatik (sekumpulan aturan inferensi dan parameter efektif). Kebalikan dari Forward-chaining adalah backwardchaining. Forward-chaining mulai memanfaatkan ketersediaan data dan 
menggunakan aturan inferensi untuk mendapatkan data lain hingga tujuan atau kesimpulan tercapai. Mesin inferensi yang memanfaatkan metode Forward-chaining akan mencari aturan inferensi hingga menemukan salah satu prasyarat yang sebenarnya (hipotesis atau klausa $I F$ $T H E N)$. Setelah menemukan aturan tersebut, mesin keputusan dapat memberikan hasil kesimpulan atau konsekuensi (THEN-IF), yang dapat menghasilkan kesimpulan baru dari data yang diberikan. Mesin akan mengulangi proses ini hingga target ditemukan. Forward-chaining adalah contoh konsep umum dari pemikiran berbasis data, yaitu fokus pemikiran dimulai dengan data yang diketahui. Tautan maju dapat digunakan di agen untuk menghasilkan kesimpulan dari persepsi yang masuk, biasanya tanpa kueri khusus[13]. Forward chaining (Pelacakan ke depan) adalah adalah metode berbasis data dimana pelacakan dimulai dengan informasi masukan dan kemudian mencoba untuk menarik kesimpulan. Pelacakan maju untuk menemukan fakta yang sesuai dengan bagian $I F$ dari aturan IF-THEN[14].

\subsection{Penelitian Terdahulu}

Penelitian yang dilakukan oleh Aditya Arif, dkk. Dengan hasil yang didapat dari sistem tersebut, masyarakat dapat mengetahui gejala-gejala kerusakan motor dan cara mengatasinya sebelum melakukan konsultasi atau perbaikan sepeda motor. Tujuan nya adalah agar dapat mendiagnosa kerusakan motor berdasarkan gejala yang diinputkan dengan menggunakan metode Foward Chaining [15].

Penelitian yang dilakukan oleh Sucipto Muhammad Sodiq, dkk. Dengan munculnya sistem pakar maka sistem dapat mendiagnosis permasalahan yang terjadi pada sepeda motor transmisi matik / CVT diharapkan terdapat dokumen pengetahuan yang dimiliki oleh para ahli sehingga pengetahuan tersebut dapat digunakan oleh orang lain / organisasi lain yang membutuhkan pengetahuan tersebut, seperti Untuk tujuan mengajar di sekolah menengah kejuruan. Teknik otomotif, teknisi yunior yang baru saja bekerja dan yang ingin mendalami teknologi CVT, sistem ini dapat dijadikan referensi ilmu pengetahuan[16].

Penelitian yang dilakukan Anggri Sartika Wiguna, dkk. Aplikasi ini dibangun untuk membantu pengguna sepeda motor injeksi matic dalam menemukan kerusakan pada motor injeksi dari gejala yang dialami. Dari hasil kuisioner aplikasi dengan metode forward-chaining dapat digunakan dari pengguna sepeda motor injeksi matic. Dapatkan kesimpulan yang tepat untuk mengetahui kerusakan sepeda motor[17].

Penelitian yang dilakukan Radia Afnur, dkk. Sistem pakar yang mampu memberikan diagnosis awal yang terjadi pada sepeda motor matic, dan agar lebih memudahkan dalam user untuk diagnosa kerusakan sepeda motor matic serta memberikan solusi, layanan dan informasi lengkap dalam melakukan perbaikan. Memberikan solusi untuk mengetahui diagnosis awal jenis kerusakan motor dengan cara menjawab pertanyaanpertanyaan tentang ciri-ciri kerusakan sepeda motor matic. Jika telah terpenuhi, dan terjawab maka akan didapat sebuah hasil jenis kerusakan apa yang dialami oleh motor dan disertai solusi yang tepat untuk membantu memperbaiki kerusakan yang terjadi pada motor tersebut[18].

\section{METODOLOGI PENELITIAN}

\subsection{Penelitian Pengumpulan Data}

Dalam penelitian ini metode pengumpulan datanya meliputi:

\section{Observasi}

Pengumpulan data dengan mengamati subjek penelitian secara langsung.

2. Wawancara

Pengumpulan data dengan melakukan Tanya jawab langsung dari lokasi penelitian.

3. Dokumentasi

Mencari data-data berkaitan dengan penelitian. Dokumentasi yang penulis kumpulkan berupa foto dan rekaman 
4. Studi Pustaka

Teori penelitian yang berkaitan dengan objek penelitian dari buku dan jurnal cetak dan non cetak.

\subsection{Use Case Diagram System}

Diagram use case menggambarkan interaksi antara user dan sistem. Dalam sistem pakar ini, ada tiga peran yang memainkan peran sebagai user. Proses use case dibagi menjadi beberapa bagian.

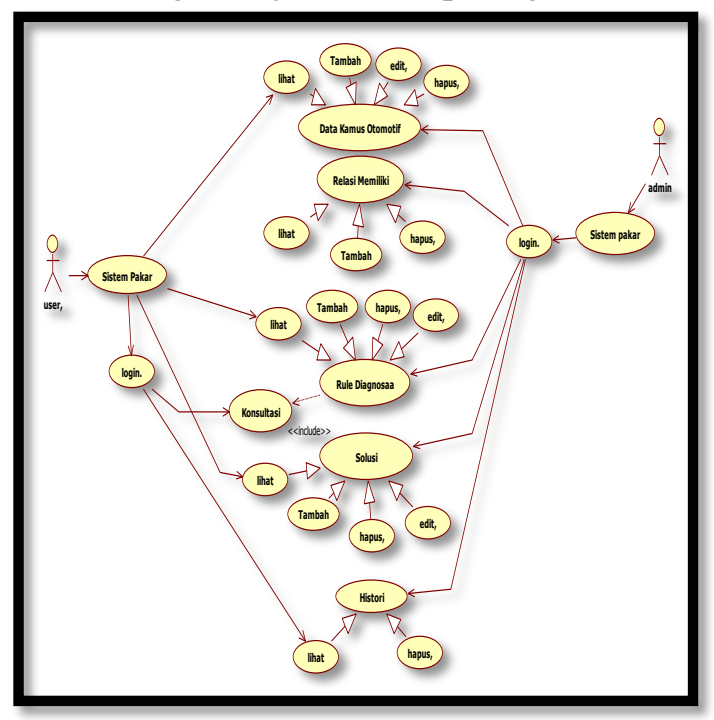

Gambar 1. Use Case Diagram

Pada gambar 1 Kegiatan aktor sebagai user adalah membuka website sistem pakar, ada beberapa menu yang bisa di akses oleh user diantaranya menu home yang berisi informasi statistik kerusakan motor yamaha matic, menu kamus otomotif yang berisi tentang informasi bagian motor yamaha matic dan user juga bisa melakukan diagnosa kerusakan setelah melakukan registrasi dan dapat Username dan Password, kemudian user melakukan login dengan menggunakan Username dan Password tersebut pada menu konsultasi. Setelah melakukan diagnosa user dapat melihat hasil diagnosa dan system akan memberikan saran atau solusi dari hasil diagnosa tersebut. Kegiatan admin melakukan login agar bisa masuk ke dalam sistem pakar, aktifitas yang di lakukan oleh admin adalah mengelola data yang ada pada sistem, menginputkan data, mengedit, maupun menghapus data pada sistem pakar.

\subsection{Activity Diagram System}

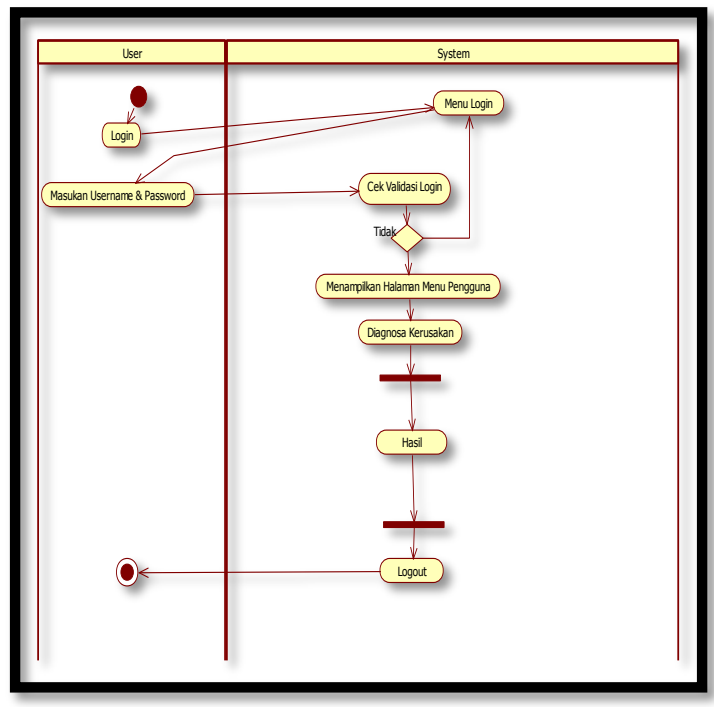

Gambar 2. Activity Diagram

Pada gambar 2 setelah user membuka halaman sistem dan memilih menu login, kemudian sistem akan menampilkan form login, user diminta memasukan username dan password, apabila user salah memasukan username dan password maka sistem akan kembali menampilkan menu form login, berbeda dengan admin, disini user bisa mengakses menu diagnosa dan melihat hasil diagnosa.

\section{HASIL DAN PEMBAHASAN}

Dari hasil pengumpulan data tersebut, tahap analisis merupakan tahap yang paling penting pada saat merancang suatu sistem, karena pada tahap ini Anda akan memahami sistem apa yang akan dibentuk, entitas apa yang akan dilibatkan, dan bagaimana memulai bentuk komunikasi antara pengguna dengan sistem. Pada sistem pakar yang menggunakan metode Foward Chaining berbasis web untuk mendiagnosis kerusakan sepeda motor yamaha ini diperlukan beberapa informasi penting yaitu:
a. Gejala kerusakan
b. Jenis kerusakan 


\subsection{Basis Pengetahuan}

Perancangan sistem pakar sebagai sistem yang mendiagnosis kerusakan sepeda motor yamaha dengan metode Foward Chaining berbasis web ditulis dalam bentuk kalimat IF (gejala) THEN (kesimpulan). Bentuk pernyataan ini menjadi $I F$ (gejala kerusakan motor) THEN (jenis kerusakan), kemudian menggunakan operator logika $A N D$ (dan) untuk menghubungkan setiap gejala jenis kerusakan. Dalam sistem pakar menggunakan fakta dan aturan sesuai dengan hasil wawancara di bengkel fredy motor pagar alam. Tabel 1 daftar jenis gejala kerusakan sepeda motor Yamaha.

Tabel 1. Jenis Gejala

\begin{tabular}{|c|l|}
\hline Kode & \multicolumn{1}{|c|}{ Gejala } \\
\hline 1 & Kekuatan Mesin lemah \\
\hline 2 & Suara mesin yang kasar \\
\hline 3 & $\begin{array}{l}\text { Knalpot mengeluarkan asap } \\
\text { putih }\end{array}$ \\
\hline 4 & Kompresi di bawah standar \\
\hline 5 & Boros Minyak Oli \\
\hline 6 & Piston Tergores \\
\hline 7 & Penurunan Akselerasi \\
\hline 8 & Terjadi Slip Pada Mesin \\
\hline 9 & Tidak Bisa Berjalan \\
\hline 10 & $\begin{array}{l}\text { Mesin Melambat pada saat } \\
\text { berjalan }\end{array}$ \\
\hline 11 & Api Busi Merah Kecil \\
\hline 12 & Mesin Mati Total \\
\hline 13 & Pemborosan bahan bakar \\
\hline 14 & Penurunan Kompresi \\
\hline 15 & Mesin tidak stabil \\
\hline 16 & Asap hitam keluar dari knalpot \\
\hline 17 & Pembekokan pada Klep \\
\hline 18 & Mesin terdengar kasar \\
\hline 19 & Kurangnya gaya pengereman \\
\hline 20 & Pengereman tidak berfungsi \\
\hline 21 & Lengket pada Rem \\
\hline 22 & $\begin{array}{l}\text { Mesin tidak dapat dihidupkan } \\
\text { dengan starter listrik }\end{array}$ \\
\hline 23 & $\begin{array}{l}\text { Suara kasar saat menggunakan } \\
\text { starter elektrik }\end{array}$ \\
\hline 24 & Generator mulai panas \\
\hline 25 & $\begin{array}{l}\text { Saluran minyak Oli tidak } \\
\text { beroperasi }\end{array}$ \\
\hline 26 & Mesin terasa panas berlebihan \\
\hline 27 & Minyak oli banyak ke bak mesin \\
\hline 28 & Terjadi Jim pada mesin \\
\hline & \\
\hline & \\
\hline 19
\end{tabular}

Pada tabel 2 menunjukan beberapa jenis kerusakan yang nantinya akan menunjang dalam memnentukan jenis gejala yang masuk ke setiap masing-masing jenis kerusakan.

Tabel 2 Jenis Kerusakan

\begin{tabular}{|c|l|}
\hline Kode & \multicolumn{1}{|c|}{ Jenis Kerusakan } \\
\hline K01 & Piston Rusak \\
\hline K02 & Van Belt Rusak \\
\hline K03 & CDI Rusak \\
\hline K04 & Klep Rusak \\
\hline K05 & Rem Rusak \\
\hline K06 & Electric Starter Rusak \\
\hline K07 & Pompa Oli Rusak \\
\hline
\end{tabular}

Berdasarkan data yang ada tentang diagnosa kerusakan sepeda motor yamaha dengan sistem aturan yang mendalam, petunjuk untuk mendiagnosis kerusakan sepeda motor yamaha untuk mendapatkan solusi yang terbaik, dari penyebab-penyebab yang bisa menghasilkan suatu kesimpulan.

Berikut adalah aturan sistem pakar yang menggunakan metode rantai positif untuk mendiagnosis kerusakan pada sepeda motor matik Yamaha dan menarik kesimpulan atau akibatnya.

Rule 1 : IF Kekuatan Mesin lemah

AND Suara mesin yang kasar $A N D$ Knalpot mengeluarkan asap putih

$A N D$ Piston Tergores

AND Kompresi di bawah standar $A N D$ Boros Minyak Oli THEN Piston Rusak

Rule 2:IF Suara mesin yang kasar AND Penurunan Akselerasi AND Terjadi Slip Pada Mesin $A N D$ Tidak Bisa Berjalan THEN Van Belt Rusak

Rule 3 : IF Kekuatan Mesin lemah AND Mesin Melambat pada saat berjalan $A N D$ Api Busi Merah Kecil AND Mesin Mati Total THEN CDI Rusak 
Rule 4 : IF Pemborosan bahan bakar AND Penurunan Kompresi

$A N D$ Mesin tidak stabil

$A N D$ Asap hitam keluar dari

knalpot

AND Pembekokan pada Klep

THEN Klep Rusak

Rule 5 : IF Mesin terdengar kasar

$A N D$ Kurangnya gaya pengereman

$A N D$ Pengereman tidak berfungsi

$A N D$ Lengket pada Rem

THEN Rem Rusak

Rule 6 : IF Mesin tidak dapat dihidupkan dengan starter listrik

$A N D$ Suara kasar saat

menggunakan starter elektrik

$A N D$ Generator mulai panas

THEN Electric Starter Rusak

Rule 7 : IF Saluran minyak Oli tidak beroperasi

AND Mesin terasa panas berlebihan $A N D$ Minyak oli banyak ke bak mesin

$A N D$ Terjadi Jim pada mesin

THEN Pompa Oli Rusak

\subsection{Rancangan Basis Pengetahuan}

Basis pengetahuan yang diperoleh dari para ahli atau sumber dokumen lain. Bahasa alami yang masih dipergunakan oleh pengetahuan harus diubah menjadi bahasa yang dapat dijadikan bahasa program oleh komputer. Basis pengetahuan memiliki tahapan untuk pengembangan, meliputi:

a. Tentukan solusi yang mungkin. Pada tahap ini, mengetahui dan mempelajari bidang pengetahuan sebagai daftar jawaban, pilihan dan saran lainnya.

b. Tentukan data yang akan dimasukan. Pada bagian ini mengidentifikasi dan mendaftarkan data yang dibutuhkan oleh sistem.

c. Garis besar pembangunan. Pada bagian ini menambahkan input data yang dibutuhkan untuk melengkapi domain dan mengatasi kesulitan penulisan aturan.

d. Untuk menggambar pohon pengetahuan, yang harus dilakukan pada tahap ini adalah membangun keputusan dan pohon pencarian. e. Buat matriks akuisisi pengetahuan. Pada bagian ini yang perlu dilakukan yaitu mendapatkan rangkaian pengetahuan dalam bentuk matriks.

f. Di bagian ini yang perlu diperhatikan dalam pengembangan perangkat lunak yaitu menulis rangkaian pengetahuan yang ada dan bisa dimengerti oleh bahasa program komputer.

Rangkaian pengetahuan yang fleksibel sehingga para ahli bisa mengubah dan menambah rangkaian pengetahuan berdasarkan data baru, dan aturan mainnya terdapat pada Tabel 3 berikut ini:

Tabel 3 Rule

\begin{tabular}{|c|c|c|c|c|c|c|c|}
\hline \multirow{3}{*}{ Gejala } & \multicolumn{7}{|c|}{ Jenis Kerusakan } \\
\hline & $\mathrm{K}$ & K & $\mathrm{K}$ & $\mathrm{K}$ & $\mathrm{K}$ & $\mathrm{K}$ & $\mathrm{K}$ \\
\hline & 01 & 02 & 03 & 04 & 05 & 06 & 07 \\
\hline 1 & $\mathrm{X}$ & $\mathrm{X}$ & $\mathrm{X}$ & & & & \\
\hline 2 & $\mathrm{X}$ & X & & & & & \\
\hline 3 & $\mathrm{X}$ & & & & & & \\
\hline 4 & $X$ & & & & & & \\
\hline 5 & X & & & & & & \\
\hline 6 & X & & & & & & \\
\hline 7 & & $X$ & & & & & \\
\hline 8 & & X & & & & & \\
\hline 9 & & X & & & & & \\
\hline 10 & & & X & & & & \\
\hline 11 & & & $X$ & & & & \\
\hline 12 & & & X & & & & \\
\hline 13 & & & & X & & & \\
\hline 14 & & & & $X$ & & & \\
\hline 15 & & & & X & & & \\
\hline 16 & & & & $X$ & & & \\
\hline 17 & & & & $\mathrm{X}$ & & & \\
\hline 18 & & & & & $X$ & & \\
\hline 19 & & & & & X & & \\
\hline 20 & & & & & $X$ & & \\
\hline 21 & & & & & X & & \\
\hline 22 & & & & & & $X$ & \\
\hline 23 & & & & & & $X$ & \\
\hline 24 & & & & & & X & \\
\hline 25 & & & & & & & X \\
\hline 26 & & & & & & & X \\
\hline 27 & & & & & & & X \\
\hline 28 & & & & & & & $\mathrm{X}$ \\
\hline
\end{tabular}




\subsection{Implementasi User Interface}

Pengguna dapat berinteraksi dengan aplikasi sistem pakar melalui akses Web. Dengan menggunakan aplikasi ini, pengguna dapat langsung berkonsultasi seperti seorang ahli / teknisi dan mendapatkan informasi tentang kerusakan motor Yamaha matic.

Pada Gambar 3 di bawah ini terdapat menu utama, pada saat mengunjungi website sistem pakar ini menu tersebut adalah halaman muka. Ada beberapa pilihan menu, seperti menu utama dengan slide dan statistik kerusakan, serta menu konsultasi dan menu kamus otomotif.

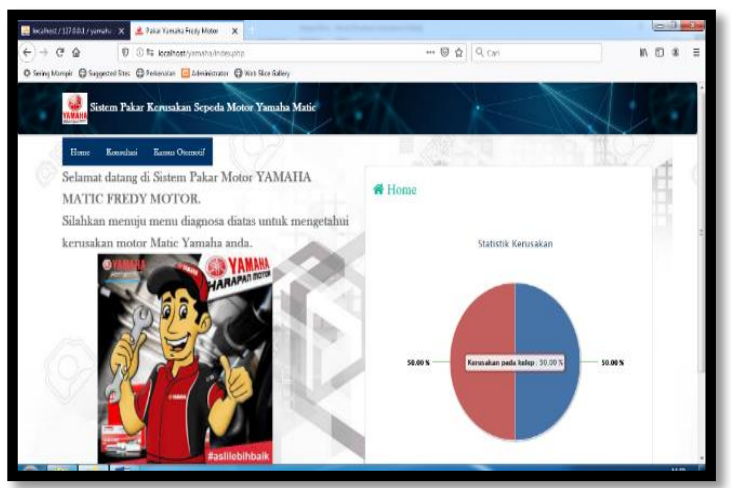

Gambar 3. Tampilan Menu Home

Pada gambar 4 berikut ini adalah menu informasi bagian dari sepeda motor matic yamaha, dimana pada menu ini berisi gambar dan tentang penjelasan dari bagian sepeda motor yamaha matic. Berikut gambar tampilannya.

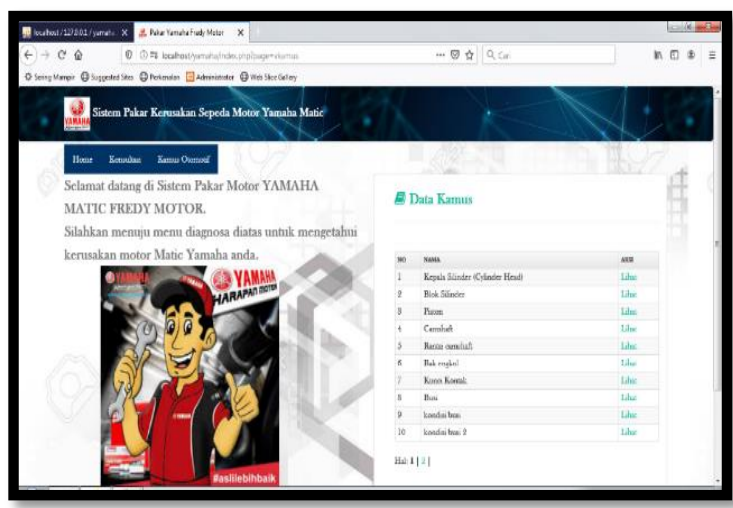

Gambar 4. Halaman Informasi Otomotif

Sebelum ke menu konsultasi, user terlebih dahulu harus mendaftarkan diri untuk mendapatkan username dan password, dapat dilihat pada gambar 5 dibawah ini.

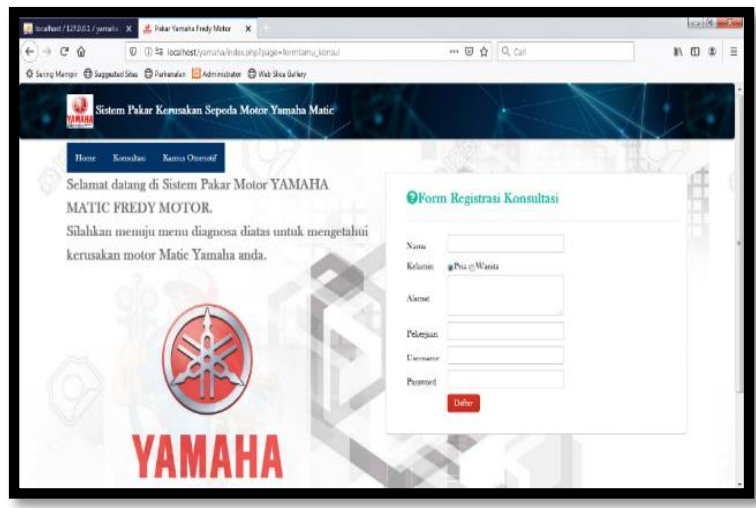

Gambar 5. Tampilan Halaman Registrasi

Jika selesai registrasi maka user akan login pada form login, tampilannya terdapat pada gambar 6 berikut.

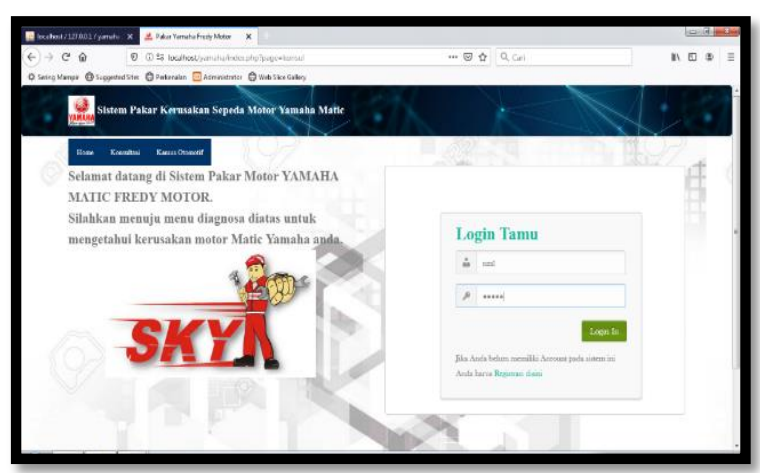

Gambar 6. Tampilan Halaman Login

Setelah login maka user akan menuju ke halaman pertanyaan, pada halaman tampilan menu pertanyaan tentang gejala kerusakan sepeda motor yamaha matic, tampilannya terdapat pada gambar 7 dibawah ini.

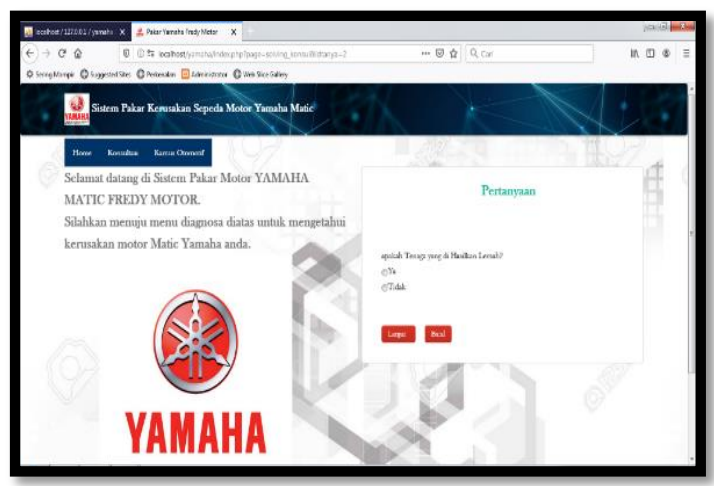

Gambar 7. Tampilan Halaman Konsultasi 
Saat semua sudah dipilih sesuai gejala yang di alami oleh user maka sistem akan menampilkan hasil dari gejala yang sudah dijawab oleh user, tampilannya terdapat pada gambar 8 berikut.

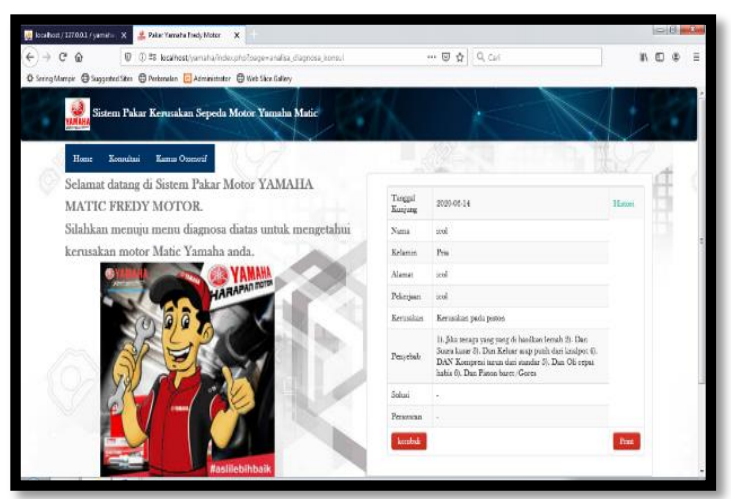

Gambar 8. Halaman Hasil Diagnosa

Pada saat user selesai melihat hasil dari diagnosa kerusakan sepeda motor yamaha matic, maka user bisa melihat histori dari diagnosa kerusakan motor yamaha matic, tampilannya seperti gambar 9 berikut.

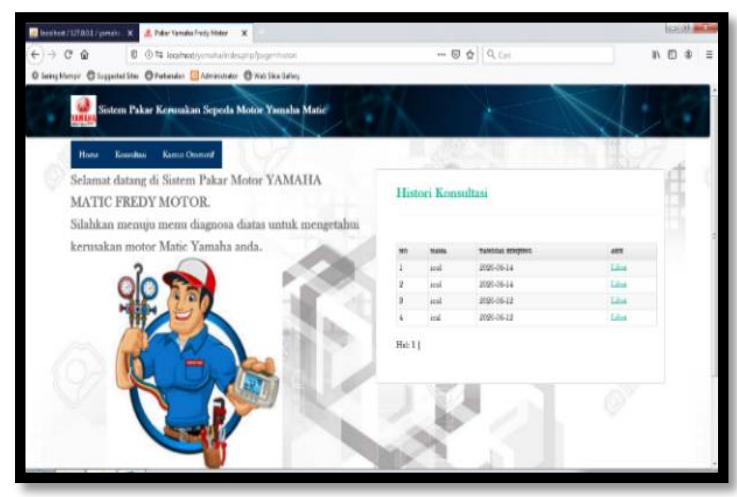

Gambar 9. Tampilan Halaman Histori

\section{KESIMPULAN}

Berdasarkan analisa dan pembahasan yang dilakukan peneliti, peneliti menarik kesimpulan, Sistem pakar tersebut dapat memberikan informasi dan diagnosis dini untuk mendiagnosis gangguan performa sepeda motor Yamaha, sehingga masyarakat dapat lebih mudah menemukan gejala-gejala gangguan performa sepeda motor Yamaha Matic dan cara penanggulangannya dan ditampilkan berbasis web dangan menggunakan bahasa pemprograman $P H P$ dan HTML. Sistem pakar dapat digunakan sebagai media untuk penerapan ilmu pakar atau pakar aplikasi kecerdasan untuk menganalisis kerusakan sepeda motor matic Yamaha dan cara penanggulangannya. Serta sistem pakar ini dapat membantu pengguna (user) untuk mempermudah mendapatkan informasi tentang kerusakan sepeda motor Yamaha matic.

\section{SARAN}

Tentunya pada penilitian ini masih terdapat kekurangan yang harus disempurnakan kedepannya seperti kerusakan yang dibahas tidak hanya kerusakan sepda motor yamaha matic, melainkan kerusakan lainny, kemudian tidak hanya mengunakan bahasa pemrograman PHP tetapi bisa pemrograman yang lain yang bisa menampilkan fitur-fitur dan tampilan lebih menarik agar lebih menarik pengguna

\section{DAFTAR PUSTAKA}

[1] R. Rusdiansyah and F. Rantau, "SISTEM PAKAR UNTUK MENDIAGNOSA KERUSAKAN MESIN SEPEDA MOTOR MATIC DENGAN METODE FORWARD CHAINING," J. Pilar Nusa Mandiri, 2018, doi: 10.33480/PILAR.V14I1.86.

[2] N. Nazarudin, A. Saputra, and H. Khumaini, "SISTEM PAKAR DIAGNOSA KERUSAKAN MESIN SEPEDA MOTOR YAMAHA DI COMPION MOTOR DUMAI," I $N F O R M A T I K A$, 2017, doi: 10.36723/juri.v9i1.86.

[3] P. Mauliana, R. Firmansyah, and N. Hunaifi, "Sistem Pakar Diagnosis Kerusakan Mobil Toyota Kijang LSX Menggunakan Metode Forward Chaining," J. Inform., 2017.

[4] F. A. Nugroho, "Perancangan Sistem Pakar Diagnosa Penyakit Jantung dengan Metode Forward Chaining," J. Inform. Univ. Pamulang, 2018, doi:

10.32493/informatika.v3i2.1431.

[5] N. Aini, R. Ramadiani, and H. R. 
Hatta, "Sistem Pakar Pendiagnosa Penyakit Tuberkulosis," Inform. Mulawarman J. Ilm. Ilmu Komput., 2017, doi: 10.30872/jim.v12i1.224.

[6] Tuslaela and D. Permadi, "Sistem Pakar Diagnosa Penyakit Gigi Dan Mulut," J. PROSISKO Vol., 2018.

[7] J. Nasir and Z. H. Gultom, "Sistem Pakar Untuk Mendeteksi Kerusakan Pada Sepeda Motor Dengan Menggunakan Metode Forward Chaining Berbasis Web," Digit. Zo. J. Teknol. Inf. dan Komun., 2018, doi: 10.31849/digitalzone.v9i1.1075.

[8] I. Wicaksono, F. N. Hakim, and V. G. Utomo, "SISTEM PAKAR DIAGNOSA KERUSAKAN PADA MOTOR MATIC VARIO BERBASIS WEB," J. Transform., 2016,

doi: 10.26623/transformatika.v13i2.327.

[9] G. Lestari, "Konsep Dasar Sistem," J. Chem. Inf. Model., 2019, doi: 10.1017/CBO9781107415324.004.

[10] B. Muslim, Yadi, and M. Harta, "Sistem Pakar Diagnosa Awal Penyakit Ginjal Berbasis Web Menggunakan PHP DAN MYSQL," J. Ilm. Betrik, 2017, doi: 10.36050/betrik.v8i03.72.

[11] G. A. D. Sugiharni and D. G. H. Divayana, "Pemanfaatan Metode Forward Chaining Dalam Pengembangan Sistem Pakar Pendiagnosa Kerusakan Televisi Berwarna," J. Nas. Pendidik. Tek. Inform., 2017, doi: 10.23887/janapati.v6i1.9926.

[12] A. S. Wiguna and I. Harianto, "SISTEM PAKAR DIAGNOSA KERUSAKAN SEPEDA MOTOR MATIC INJEKSI

MENGGUNAKAN METODE FORWARD CHAINING BERBASIS ANDROID," SMARTICS J., 2017, doi: 10.21067/smartics.v3i1.1933.

[13] I. Akil, "Analisa Efektifitas Metode Forward Chaining Dan Backward Chaining Pada Sistem Pakar," None, 2017.

[14] N. Merlina, "Sistem Pakar Diagnosa Kerusakan Pada Mesin Pendingin
Ruangan Dengan Metode Forward Chaining," None, 2016.

[15] A. Prapanca and M. Arif, "RANCANG BANGUN SISTEM PAKAR UNTUK DIAGNOSA KERUSAKAN SEPEDA MOTOR DENGAN METODE FORWARD CHAINING," J. Manaj. Inform., 2015.

[16] S. M. Sodiq and Q. Shinta, "Rancang Bangun Sistem Pakar Untuk Diagnosa Kerusakan Pada Motor Matic Dengan Metode Forward Chaining," J. Teknol. Inf. dan Komun., 2016.

[17] A. Sartika Wiguna and I. Harianto, "Sepeda Motor Matic Injeksi Menggunakan Metode Forward," SMARTICS J., 2017.

[18] R. Afnur, T. Sriwahyuni, and A. Hadi, "Rancang bangun aplikasi sistem pakar untuk diagnosis kerusakan sepeda motor matic menggunakan metode forward chaining," Voteknika, 2016. 